\title{
Cigarette smoking and human papillomavirus in patients with reported cervical cytological abnormality
}

\author{
M P M Burger, H Hollema, A S H Gouw, W J L M Pieters, W G V Quint
}

\begin{abstract}
Objective-To assess the relation between two risk factors for cervical neoplasia: smoking and infection with oncogenic human papillomavirus. It has been suggested that smoking causes a local immunological defect, which could facilitate the infection and persistence of human papillomavirus.

Design-Cross sectional epidemiological study. Completion of a structured questionnaire by the patients, analysis of cervical scrapes for human papillomavirus, and morphological examination of biopsy specimens.
\end{abstract}

Setting-Outpatient gynaecological clinic.

Subjects-181 women with a report of cervical cytological abnormality.

Main outcome measures-Prevalence of infection with oncogenic hunıan papillomavirus and smoking habits.

Results-Oncogenic human papillomavirus was found in the cervix of $26(41 \%)$ of the 63 women who did not smoke, $22(58 \%)$ of the 38 who smoked $1-10$ cigarettes a day, $28(61 \%)$ of the 46 who smoked 11-20 cigarettes a day, and $26(76 \%)$ of the 34 who smoked $\geqslant 21$ cigarettes a day. The prevalence of the virus thus increased in accordance with the number of cigarettes smoked $(p=0.001)$. This relation remained after adjustment for age at first intercourse and lifetime number of sexual partners. Of the 63 non-smokers, 23 had previously smoked at least 10 cigarettes a day at some time. Of these 23 women, 14 $(61 \%)$ had oncogenic human papillomavirus in their cervix. Of the $\mathbf{4 0}$ women who had never smoked at least 10 cigarettes a day, $12(30 \%)$ had the virus. The prevalence of oncogenic human papillomavirus in non-smokers therefore depended on previous smoking habits $(p=0.03)$.

Conclusion-The dose dependent effect of cigarette smoking on the occurrence of oncogenic human papillomavirus favours a causal relation between these risk factors for cervical neoplasia.

Department of Obstetrics and Gynaecology, University Hospital, NL-9713 EZ Groningen, Netherlands

M P M Burger, gynaecologist

Department of Pathology, University Hospital H Hollema, pathologist A S H Gouw, pathologist

Department of Pathology, $9675 \mathrm{HJ}$ Winschoten

W J L M Pieters, pathologist

Department of Molecular Biology, Diagnostic Centre SSDZ, 2625 AD Delft

W G V Quint, molecular biologist

Correspondence to: Dr Burger.

BMF 1993;306:749-52 potential of many other virus types mainly found in association with mild to moderate dysplastic smears is uncertain. ${ }^{4}$

Cigarette smoking is a risk factor for cervical neoplasia.$^{6}$ It has been associated with the presence of cervical human papillomavirus in patients at student health clinics. ${ }^{7}$ Another risk factor for cervical neoplasia is sexual behaviour: a woman's having intercourse before the age of 17 was the most powerfully discriminating variable in nearly all the studies where this has been investigated, and a history of multiple sexual partners is an important supporting variable. ${ }^{8}$ The association between smoking and cervical neoplasia, however, remains after adjustment has been made for such sexual risk factors. ${ }^{9-12}$

We performed a cross-sectional epidemiological study on 181 women with a report of cervical cytological abnormality in order to find out whether the presence of oncogenic human papillomavirus was associated with the grade of the neoplastic lesion; whether smoking was associated with the grade of the neoplastic lesion; and whether smoking was associated with the presence of oncogenic human papillomavirus.

\section{Patients and methods}

PATIENTS

We recruited patients from the outpatient clinic of the department of gynaecology, University Hospital, Groningen. Some had been referred by their general practitioners because of a report of cervical cytological abnormality, and in others a cytological abnormality had been discovered during gynaecological examination. Patients were eligible for participation in the study if two cervical smears indicated mild or moderate dysplasia or one smear indicated severe dysplasia or carcinoma in situ. These cytological criteria for eligibility correspond with the grounds for colposcopy as agreed by cytopathologists and gynaecologists in the Netherlands.

The interval between the two smears indicating mild or moderate dysplasia was a maximum of one year. We requested smears that had not been initially examined at our cytology department for review, and our cytologist's readings were definitive. Patients were ineligible if they had previously undergone a colposcopic examination because of a report of abnormal cytology, if their cervical smear was taken during pregnancy, or if their cervical smear indicated atypical endocervical cylindrical epithelium.

From 1 September 1988 to 1 May 1991, 194 consecutive patients were eligible for participation in the study and were invited to the outpatient clinic for an extra visit to answer a structured questionnaire and to have a cervical scrape taken for analysis for human papillomavirus. Thirteen patients did not enter the study: two did not want to, two were pregnant at the time of colposcopy, and nine were not treated in accordance with the study protocol (no cervical scrape or no biopsy specimen was taken or no treatment was given when the biopsy specimen showed cervical intraepithelial neoplasia). Therefore, 181 patients were included in the study. 
QUESTIONNAIRE

We asked the women the average number of cigarettes they smoked a day and asked those who did not smoke whether they had ever smoked at least 10 cigarettes a day. We also asked the patients their age at their first sexual intercourse and their lifetime number of sexual partners. We had told the women beforehand that the questionnaire contained intimate questions and that they were not obliged to answer.

ANALYSIS FOR HUMAN PAPILLOMAVIRUS

We scraped the cervix with the blunt and pointed ends of a wooden cervical spatula and with an endocervical brush. We suspended the scraped cells in $5 \mathrm{ml}$ phosphate buffered saline, $\mathrm{pH} 7 \cdot 2$, supplemented with merthiolate 1:10000 vol/vol and sent the cell suspension to the laboratory for processing the next morning. The polymerase chain reaction was performed for human papillomavirus types 6 and 11, 16, 18, and 33 as described previously. ${ }^{1314}$ The laboratory staff were unaware of the histological reports.

\section{MORPHOLOGICAL EXAMINATION}

Four weeks after the cervix had been scraped, we took colposcopically directed biopsy specimens and, in the case of an endocervical position of the neosquamocolumnar junction, performed endocervical curettage. If cervical intraepithelial neoplasia was diagnosed from the tissue specimens we excised the whole transformation zone about 4-6 weeks later by low voltage diathermy ablation or cold knife conisation. The diathermy loop was used when the neosquamocolumnar junction could be visualised entirely and did not extend up into the canal more than $5 \mathrm{~mm}$ from the anatomical os externum.

One pathologist who was unaware of the virus types found in the cervical scrapes examined all the biopsy specimens and the excised tissues from the patients. Cervical intraepithelial neoplasia was diagnosed and graded according to the criteria of the World Health Organisation. The cervical neoplasia was classified according to the most severe lesion found by histological examination.

\section{STATISTICAL ANALYSIS}

Using SPSS software, we analysed differences between two groups of patients in the frequency of smokers and the presence of human papillomavirus by means of the $x^{2}$ test with Yates's correction for two independent samples. We analysed differences between multiple groups in age distribution and the number of cigarettes smoked daily by means of the Kruskal-Wallis one way analysis of variance.

We performed $2 \times \mathrm{k}$ table analyses of the presence of oncogenic human papillomavirus in relation to the categories of cervical neoplasia and the presence of the virus in relation to the number of cigarettes smoked per day. For this we used the EGRET software, in which the formula for the $\chi^{2}$ test for trend in stratified and unstratified analysis was taken from Breslow and Day, ${ }^{15}$ The test was used with continuity correction, and values of $p \leqslant 0.05$ were considered to be significant.

\section{Results}

DIAGNOSES

The final histological diagnoses were no neoplasia (15 patients), cervical intraepithelial neoplasia grade I (19), cervical intraepithelial neoplasia grade II (28), cervical intraepithelial neoplasia grade III (108), and microinvasive carcinoma (11). The patients were aged 20-67 with a mean age of 34.4 (SD 7.9) years. There was no difference between the categories of the diagnosis with regard to age distribution $\left(\chi^{2}=3 \cdot 11\right.$, $\mathrm{df}=4, \mathrm{p}=0.54 ;$ Kruskal-Wallis one way analysis of variance).

\section{HUMAN PAPILLOMAVIRUS AND CERVICAL NEOPLASIA}

Table I shows the virus types detected in the histological categories. A benign human papillomavirus (type 6 or 11) was the only virus type found in one patient and was found in conjunction with oncogenic virus types in another three patients. One or more oncogenic human papillomavirus (type 16,18 , or 33 ) was found in $4(27 \%)$ of the 15 patients without neoplasia, $6(32 \%)$ of the 19 with cervical intraepithelial neoplasia grade I, $12(43 \%)$ of the 28 with cervical intraepithelial neoplasia grade II, $73(68 \%)$ of the 108 with cervical intraepithelial neoplasia grade III, and $7(64 \%)$ of the 11 with microinvasive carcinoma. Thus the prevalence of oncogenic human papillomavirus increased with the severity of the neoplastic lesion $\left(\chi^{2}=14.97, \mathrm{df}=1, \mathrm{p}<0.001 ; \chi^{2}\right.$ test for trend). Of the 102 patients positive for oncogenic human papillomavirus, $80(78 \%)$ had cervical intraepithelial neoplasia grade III or a more severe lesion.

TABLE I-Types of human papillomavirus diagnosed in patients with a report of cervical cytological abnormality

\begin{tabular}{|c|c|c|c|c|c|c|}
\hline \multirow{2}{*}{$\begin{array}{l}\text { Type of } \\
\text { human } \\
\text { papillomavirus }\end{array}$} & \multicolumn{5}{|c|}{ Type of neoplasia } & \multirow[b]{2}{*}{ Total } \\
\hline & None & $\begin{array}{c}\text { CIN } \\
\text { grade I }\end{array}$ & $\begin{array}{c}\text { CIN } \\
\text { grade II }\end{array}$ & $\underset{\text { grade III }}{\mathrm{CIN}}$ & MIC & \\
\hline $\begin{array}{l}\text { None } \\
6 / 11\end{array}$ & 11 & $\begin{array}{r}12 \\
1\end{array}$ & 16 & 35 & 4 & $\begin{array}{r}78 \\
1\end{array}$ \\
\hline $6 / 11,16$ & & & 1 & & 1 & 2 \\
\hline $6 / 11,16,18$ & 1 & & & & & 1 \\
\hline 16 & 1 & 1 & 6 & 59 & 5 & 72 \\
\hline 16,18 & & 1 & 1 & 3 & & 5 \\
\hline 16,33 & & & & 1 & & 1 \\
\hline 18 & 1 & 3 & 3 & 6 & 1 & 14 \\
\hline 18,33 & & 1 & & & & 1 \\
\hline 33 & 1 & & 1 & 4 & & 6 \\
\hline Total & 15 & 19 & 28 & 108 & 11 & 181 \\
\hline
\end{tabular}

$\mathrm{CIN}=$ cervical intraepithelial neopla

SMOKING AND CERVICAL NEOPLASIA

Altogether $118(65 \%)$ of the 181 patients smoked at least one cigarette a day, and the proportion of smokers in each of the histological categories was similar: 10 $(67 \%)$ of the 15 without neoplasia, $12(63 \%)$ of the 19 with cervical intraepithelial neoplasia grade I, 18 (64\%) of the 28 with cervical intraepithelial neoplasia grade II, $71(66 \%)$ of the 108 with cervical intraepithelial neoplasia grade III, and $7(64 \%)$ of the 11 with microinvasive carcinoma. No significant difference was found between the histological categories with regard to the number of cigarettes smoked a day $\left(\chi^{2}=5.07, \mathrm{df}=4, \mathrm{p}=0.27\right.$; Kruskal-Wallis one way analysis of variance).

\section{SMOKING AND HUMAN PAPILLOMAVIRUS}

We found oncogenic human papillomavirus in the cervices of $76(64 \%)$ of the 118 smokers and $26(41 \%)$ of the 63 non-smokers, a significant difference $\left(\chi^{2}=8.02\right.$, $\mathrm{df}=1, \mathrm{p}=0.005 ; \chi^{2}$ test for two proportions). To look for a dose-response relation we grouped the patients according to the number of cigarettes they smoked a day: none, $1-10,11-20$, and $\geqslant 21$. Table II shows that the frequency of oncogenic virus increased signifi-

TABLE II-Occurrence of oncogenic human papillomavirus (types 16, 18 , or 33) in patients with report of cervical cytological abnormality in relation to number of cigarettes smoked

\begin{tabular}{lc}
\hline No of cigarettes smoked a day & $\begin{array}{c}\text { No (\%) of patients } \\
\text { with oncogenic virus }\end{array}$ \\
\hline 0 & $26 / 63(41)$ \\
$1-10$ & $22 / 38(58)$ \\
$11-20$ & $28 / 46(61)$ \\
$\geqslant 21$ & $26 / 34(76)$
\end{tabular}

Test for trend; $\chi^{2}=10 \cdot 75, \mathrm{df}=1, \mathrm{p}=0.001$. 
cantly in accordance with the number of cigarettes smoked a day.

We analysed the dose-response relation with adjustment for the patients' age at first intercourse and lifetime number of sexual partners. Nine patients did not give their number of sexual partners and one of them did not tell her age at first intercourse. We therefore performed the analysis on 172 patients: the median age at first intercourse was 17 (interquartile range 16-19) years, and the median number of sexual partners was 4 (interquartile range 2-10) partners. For the analysis we grouped patients according to age at first intercourse $(\leqslant 17$ or $\geqslant 18)$ and lifetime number of sexual partners $(1-2,3-4,5-10$, and $\geqslant 11)$. After adjustment for these sexual risk factors we found that the dose-response relation between the number of cigarettes smoked a day and the presence of oncogenic human papillomavirus was still significant $\left(\chi^{2}=10 \cdot 90\right.$, $\mathrm{df}=1, \mathrm{p}<0.001$ )

We also investigated whether this dose-response relation depended on the histological severity of the lesion. Since we had found that the analysis was hardly affected by adjustment for sexual risk factors we performed a non-adjusted analysis on the entire group of 181 women. We grouped patients into those with no or low grade lesions (up to and including cervical intraepithelial neoplasia grade II) and those with more severe lesions (cervical intraepithelial neoplasia grade III or microinvasive carcinoma). Table III shows that the dose-response relation between the number of cigarettes smoked a day and the occurrence of oncogenic human papillomavirus in the cervix was significant in both groups.

TABLE III-Occurrence of oncogenic human papillomavirus (types 16 18 , or 33) in patients with report of cervical cytological abnormality in relation to number of cigarettes smoked: patients divided into two groups according to final diagnosis

\begin{tabular}{lcc}
\hline & \multicolumn{2}{c}{ No (\%) of patients with oncogenic virus } \\
\cline { 2 - 3 } $\begin{array}{l}\text { No of cigarettes } \\
\text { smoked a day }\end{array}$ & $\begin{array}{c}\text { With no lesion or low } \\
\text { grade lesion }\end{array}$ & With severe lesion $\dagger$ \\
\hline 0 & $4 / 22(18)$ & $22 / 41(54)$ \\
$1-10$ & $6 / 13(46)$ & $16 / 25(64)$ \\
$11-20$ & $6 / 18(33)$ & $22 / 28(79)$ \\
$\geqslant 21$ & $6 / 9(67)$ & $20 / 25(80)$ \\
\hline Test for trend & $\mathrm{p}=0 \cdot 038 \neq$ & $\mathrm{p}=0 \cdot 013 \S$ \\
\hline *Up to and including cervical intraepithelial neoplasia grade II. \\
$\dagger$ Cervical intraepithelial neoplasia grade III or microinvasive tumour. \\
$\ddagger \chi^{2}=4 \cdot 30, \mathrm{df}=1$.
\end{tabular}

Of the 63 women who did not smoke, 23 women had smoked at least 10 cigarettes a day at some time. Of these 23 women, $14(61 \%)$ had oncogenic human papillomavirus in their cervix. Of the remaining 40 women who did not currently smoke and who had never smoked at least 10 cigarettes a day, only $12(30 \%)$ had oncogenic papillomavirus. This difference was statistically significant $\left(\chi^{2}=4.54, \mathrm{df}=1, \mathrm{p}=0.033 ; \chi^{2}\right.$ test for two proportions).

\section{Discussion}

We studied only newly diagnosed cases of cervical abnormality because the persistence or recurrence of cervical neoplasia might also be affected by the factors under study. Pregnant patients were excluded because biopsy and treatment are usually postponed until after delivery. Because of possible biological differences in the development of squamocellular and adenocellular cervical neoplasia we also excluded any patients with atypical endocervical cylindrical cells in the smear. For the detection and typing of human papillomavirus we used cervical scrapes instead of biopsy specimens. In situ hybridisation studies have shown that human papillomavirus can be detected only within lesions and not in adjacent normal epithelium. ${ }^{1617}$ The probability of missing a cervical infection is possibly higher when using biopsy specimens because of inevitable sampling errors. Our data cannot be compared directly to those of other investigators because the reported frequencies of human papillomavirus in cervical lesions vary widely because of differences in selecting patients, in the materials analysed, in detection techniques, and in the geographical occurrence of virus types. ${ }^{18}$ The frequencies of the virus types observed in our patient group match the findings of another group of Dutch investigators. ${ }^{4}$

We found that $80 / 102(78 \%)$ patients positive for oncogenic human papillomavirus had cervical intraepithelial neoplasia grade III or a more severe lesion. Since patients with all three grades of cervical intraepithelial neoplasia had similar ages this suggests that many infections with oncogenic human papillomavirus apparently led directly to cervical intraepithelial neoplasia grade III. Campion et al suggested that human papillomavirus infections progress rapidly from grade I to grade III of cervical intraepithelial neoplasia, ${ }^{19}$ but their study was methodologically flawed in that grade I lesions were diagnosed by colposcopy while grade III lesions were later diagnosed by histology. The features that can be seen by colposcopy do not, however, correspond well with the severity of histological abnormality. ${ }^{20}$

We found that $65 \%$ of the patients smoked at least one cigarette a day, a proportion nearly twice as high as that in the general population. According to Dutch health statistics from $1990,38 \%$ of women aged $20-34$ and $36 \%$ of women aged $35-49$ smoke. ${ }^{21}$ There are two possible explanations for the association of smoking with cervical neoplasia. Firstly, chemical carcinogens in tobacco smoke might directly induce cervical carcinogenesis. By means of the Ames test, Holly et al have shown that women who smoke are more likely to have mutagenic cervical fluids than non-smokers, ${ }^{22}$ and nicotine and cotinine have been found in the mucous secretions of the uterine cervix of smokers. ${ }^{23}$ Secondly, cigarette smoking might produce a local immunological defect. Smoking is associated with a significant and dose dependent decrease in the concentration of antigen presenting Langerhans' cells in the normal cervical epithelium..$^{24}$

We did not find an association between smoking and the grade of cervical intraepithelial neoplasia, and so our data do not support the hypothesis that cigarette smoke has a direct mutagenic effect on the cervical epithelium. We did, however, find a significant doseresponse relation between the number of cigarettes smoked daily and the presence of oncogenic human papillomavirus in the cervical lesion. Such a graded response according to exposure can strengthen inferences of causality. ${ }^{25}$ The relation remained after adjustment for sexual risk factors, indicating a significant independent effect of smoking. We also found that the presence of human papillomavirus in the cervix of nonsmokers was significantly associated with a history of smoking. Our findings support the suggestion that smoking might produce a local immunological defect, which could facilitate the infection and persistence of human papillomavirus. ${ }^{24}$

The dose-response relation between the number of cigarettes smoked daily and the presence of oncogenic human papillomavirus was found both in the group with no or low grade lesions and in the group with more severe lesions. This confirms that lesions associated with one particular virus type may show diverse morphological characteristics. Possible explanations for this diversity are the physical state of the virus (whether it is extrachromosomal or integrated into the host cell chromosomes), ${ }^{26}$ the topographical 
position of the lesion on the cervix, ${ }^{27}$ and the presence of possible cofactors such as herpes viruses in carcinogenesis.

1 Richart RM. Cervical intraepithelial neoplasia: a review. In: Sommers SC, ed. Pathology annual, 1973. New York: Appleton-Century-Crofts, 1973:301-28. De Villiers EM. Heterogeneity of the human papillomavirus group. $f$ Virol 1989;63:4898-903.

3 Ikenberg $\mathrm{H}$. Human papillomavirus DNA in invasive genital carcinomas. In: Gross G, Jablonska S, Pfister H, Stegner HE, eds. Genital papillomavinu infections. Berlin: Springer Verlag, 1990:87-112.

4 Van den Brule AJC, Snijders PJF, Gordijn RLJ, Bleker OP, Meijer CJLM, Walboomers JMM. General primer-mediated polymerase chain reaction permits the detection of sequenced and still unsequenced human papillomapermits the detection of sequenced and still unsequenced human papilloma-
virus genotypes in cervical scrapes and carcinomas. Int 7 Cancer 1990;45 virus

5 Bennett Jenson A, Lancaster WD. Association of human papillomavirus with benign, premalignant, and malignant anogenital lesions. In: Pfister $\mathrm{H}$, ed. Papillomaviruses and human cancer. Boca Raton, Florida: CRC Press, 1990:12-43.

6 Winkelstein W Jr. Smoking and cervical cancer--current status: a review. Am f Epidemiol 1990;131:945-57.

7 Rohan T, Mann V, McLaughlin J, Hamish DG, Yu H, Smith D, et al. PCR detected genital papillomavirus infection: prevalence and association with risk factors for cervical cancer. Int 9 Cancer 1991;49:856-60.

8 Rotkin ID A comparison review of key epidemiologic studies in cervical cancer related to current searches for transmissible agents. Cancer Res 1973;33:1353-67.

9 Clarke EA, Morgan RW, Newman AC. Smoking as a risk factor in cancer of the cervix: additional evidence from a case-control study. $A m \mathcal{F}$ Epidemiol 1982;115:59-66.

10 Lyon JL, Gardner JW, West DW, Stanish WM, Hebertson RM. Smoking and carcinoma in situ of the uterine cervix. Am $\mathcal{F}$ Public Health 1983;73:558-62

11 Trevathan E, Layde P, Webster LA, Adams JB, Benigno BB, Ory H Cigarette smoking and dysplasia and carcinoma in situ of the uterine cervix IAMA 1983;250:499-502.

12 Brinton LA, Schairer C, Haenszel W, Stolley P, Lehman HF, Levine R, et al. Cigarette smoking and invasive cervical cancer. $f A M A$ 1986;255:3265-9.

13 Melchers W, Van den Brule A, Walboomers J, De Bruin M, Burger M, Herbrink $P$, et al. Increased detection rate of human papillomavirus in cervical scrapes by the polymerase chain reaction as compared to modified FISH and Southern-blot analysis. $\mathcal{F}$ Med Virol 1989;27:329-35.

14 Claas E, Melchers W, van den Linden J, Lindeman J, Quint W. Human papillomavirus detection in paraffin embedded cervical carcinomas and their metastases by the polymerase chain reaction. Am f Pathol 1989;135:703-9.

15 Breslow NE, Day NE. Statistical methods in cancer research. Vol 1. The analyis f case-coln of case-control studies. Lyons: International Agency to

16 Comelissen MTE, Van den Tweel JG, Struyk APHB, Jebbink MF, Briët M Van der Noordaa J, et al. Localization of human papillomavirus type 16 Van der Noordaa J, et al. Localization of human papillomavirus type 16
DNA using the polymerase chain reaction in the cervix uteri of women with DNA using the polymerase chain reaction in the cervix uteri of
cervical intraepithelial neoplasia. $f$ Gen Virol 1989;70:2555-62.

17 Syrjänen K, Syriänen S. Concept of the existence of human papillomavirus (HPV) DNA in histologically normal squamous epithelium of the genital tract should be re-evaluated. Acta Obstet Gynecol Scand 1989;68:613-7.

18 Zur Hausen H. Papillomavirus in anogenital cancer: the dilemma of epidemiologic approaches. I Natl Cancer Inst 1989;81:1680-2.

19 Campion MJ, McCance DJ, Cuzick J, Singer A. Progressive potential of mild cervical atypia: prospective cytological and virological study. Lancet 1986;ii 237-40.

20 Barrasso R, Coupez F, Ionesco M, De Brux J. Human papilloma viruses and cervical intraepithelial neoplasia: the role of colposcopy. Gynecol Oncol 1987;27:197-207.

21 Dutch Foundation of Public Health and Smoking. Annual Repon 1990. The Hague: DFPHS, 1991

22 Holly EA, Perrakis NL, Friend NF, Sarles DL, Lee R, Flander LB. Mutagenic mucus in the cervix of smokers. $\mathcal{F}$ Natl Cancer Inst 1986;76: 983-6.

23 Sasson IM, Haley NJ, Hoffmann D, Wynder EL, Hellberg D, Nilsson S Cigarette smoking and neoplasia of the uterine cervix: smoke constituents in cervical mucus. N Engl f Med 1985;312:315-6.

24 Barton SE, Maddox PH, Jenkins D, Edwards R, Cuzick J, Singer A. Effect of cigarette smoking on cervical epithelial immunity: a mechanism for neoplastic change? Lancet 1988;ii:652-4.

25 Kramer MS. Clinical epidemiology and biostatistics. Berlin: Springer Verlag, 1988:60

26 Richart RM. A modified terminology for cervical intraepithelial neoplasia. Obstet Gynecol 1990;75:131-3.

27 Saito K, Saito A, Fu YS, Smotkin D, Gupta J, Shah K. Topographic study of cervical condyloma and intraepithelial neoplasia. Cancer 1987;59:2064-70.

(Accepted 31 December 1992)

\title{
Randomised comparison of combination chemotherapy plus supportive care with supportive care alone in patients with metastatic colorectal cancer
}

\author{
Werner Scheithauer, Harald Rosen, Gabriela-Verena Kornek, Christian Sebesta, Dieter Depisch
}

Division of Oncology, Department of Internal Medicine I, Vienna University Medical School, A-1090 Vienna, Austria Werner Scheithauer, senior lecturer

Gabriela-Verena Kornek, medical assistant

\section{Department of}

Gastroenterology,

Hanusch Hospital, A-1140

Vienna, Austria

Harald Rosen, senior

physician

Christian Sebesta, senior

plivsician

Department of Surgery,

Weiner Neustadt General

Hospital, A-2700 Weiner

Neustadt, Austria

Dieter Depisch, professor

Correspondence to:

Dr Scheithauer.

BMF 1993;306:752-5
Abstract

Objectives-To compare the length of survival and quality of life in patients given combination chemotherapy in addition to supportive care and in patients given only supportive care.

Design-Randomised study.

Setting-Gastrointestinal oncology departments.

Patients-40 previously untreated patients with histologically confirmed, measurable colorectal cancer that was locally recurrent or metastatic.

Interventions-Patients were allocated randomly to receive chemotherapy or only supportive care in a ratio of 2:1 according to performance status, metastatic disease of the liver, and weight loss in the six months before entering the study. Chemotherapy consisted of four week cycles of intravenous leucovorin $\left(200 \mathrm{mg} / \mathrm{m}^{2} /\right.$ day $)$ followed by 5 -fluorouracil $\left(550 \mathrm{mg} / \mathrm{m}^{2} /\right.$ day) and cisplatin $\left(20 \mathrm{mg} / \mathrm{m}^{2} /\right.$ day $)$, each drug being given on the first four days of the cycle.

Main outcome measures-Length of survival and quality of life score with an optimised functional living index-cancer scale.

Results-Overall survival was significantly longer for patients given chemotherapy $(11.0$ months) than for those receiving supportive care alone $\mathbf{5 \cdot 0}$ months; $p=0 \cdot 006$ ). Despite common association of chemotherapy with mild to moderate gastrointestinal symptoms, there was no significant difference between the two groups in global or subgroup quality of life scores. In patients with abnormal scores before treatment, quality of life seemed better in the chemotherapy arm.

Conclusions-In this sample of patients with dis- seminated colorectal cancer the chemotherapy regimen was an effective form of palliative treatment.

\section{Introduction}

Chemotherapeutic management of advanced colorectal cancer has been a challenge to medical oncologists for the past three decades. Although tumours in $15-20 \%$ of patients have responded to fluorinated pyrimidines, in particular 5-fluorouracil, there has been no evidence of improved survival.' Empirically derived combinations of chemotherapeutic drugs have given disappointing results. ${ }^{2}$ Recent attempts to enhance the therapeutic activity of 5fluorouracil have focused on biochemical modulation: several randomised studies have shown that its effect is greater when used in combination with leucovorin.' The optimal dose, schedule, and route of administration, however, have not been established. Complete response is rare, and the improvement in median survival seems small. Furthermore, most 5 -fluorouracil and leucovorin dose schedules have a high incidence of severe gastrointestinal side effects ${ }^{3}$ and may thus interfere with the patients' quality of life, one of the most important aspects to be considered in palliative treatment.

Because of uncertainty about the true palliative benefit of combined regimens we conducted a randomised study of the effects of chemotherapy and supportive care on survival and quality of life of patients with colorectal cancer. The chemotherapeutic regimen chosen was a combination of 5-fluorouracil and leucovorin with cisplatin. Cisplatin was included 